P0199

\title{
A NEW WEARABLE DEVICE FOR MEASURING PUPILAR ILLUMINANCE AND EVALUATE DISCOMFORT GLARE
}

\author{
Maíra Vieira Dias et al.
}

DOI 10.25039/x46.2019.PO199

from

CIE x046:2019

\section{Proceedings}

of the

29th CIE SESSION

Washington D.C., USA, June 14 - 22, 2019

(DOI 10.25039/x46.2019)

The paper has been presented at the 29th CIE Session, Washington D.C., USA, June 14-22, 2019. It has not been peer-reviewed by CIE.

(c) CIE 2019

All rights reserved. Unless otherwise specified, no part of this publication may be reproduced or utilized in any form or by any means, electronic or mechanical, including photocopying and microfilm, without permission in writing from CIE Central Bureau at the address below. Any mention of organizations or products does not imply endorsement by the CIE.

This paper is made available open access for individual use. However, in all other cases all rights are reserved unless explicit permission is sought from and given by the $\mathrm{CIE}$.

CIE Central Bureau

Babenbergerstrasse 9

A-1010 Vienna

Austria

Tel.: +43 17143187

e-mail: ciecb@cie.co.at

www.cie.co.at 


\title{
A NEW WEARABLE DEVICE FOR MEASURING PUPILAR ILLUMINANCE AND EVALUATE DISCOMFORT GLARE
}

\author{
Dias, M.V. ${ }^{1}$, Motamed, A. ${ }^{2}$, Scarazzato, P.S. ${ }^{1}$, Scartezzini, J.L. ${ }^{2}$ \\ ${ }^{1}$ School of Civil Engineering, Architecture and Urban Design, University of Campinas \\ (UNICAMP), Campinas, BRAZIL, ${ }^{2}$ Laboratory of Solar Energy and Building Physics (LESO- \\ PB), École Polytechnique Fédérale de Lausanne (EPFL), Lausanne, SWITZERLAND \\ mairavd@yahoo.com.br
}

DOI 10.25039/x46.2019.PO199

\begin{abstract}
Throughout the 20th-century lighting systems designed for office buildings have focused mainly on the amount of light needed for work, based on visual criteria: illuminance in the horizontal plane was the most important design objective while non-visual biological effects were not considered. This paper presents a research carried out at LESO solar experimental building at EPFL (Lausanne, Switzerland), designed to investigate how light flux reaches the user's eyes. During 5 full days in January 2017, two young females with normal vision used each one a wearable device named OcuLux, which has an RGB sensor attached to the glass frames for registering continuously the actual pupilar illuminance (lux). At the end of each day the participants answered an online questionnaire based on Office Lighting Survey. Relative position of participants implies in different light doses. Qualitative and quantitative data were important to understand how light reaches the humans eyes.
\end{abstract}

Keywords: Pupilar Illuminances, Discomfort Glare, Wearable Device.

\section{Introduction}

Light is not only responsible for the imaging process that promotes the vision, but also for nonvisual biological effects that may affect human physiology and behaviour, such as improvement of alertness, cognitive performance, and mood. So, for a better understanding about non-visual biological effects, it is important to investigate the light flux that reaches the user's eyes.

The working environment of offices has changed its nature over the last years. This has been happening not because the purpose of office work has changed but rather because the means to do the work have changed. The introduction of the personal computer in the workplace was the beginning of this change, which continues due to emerging technologies (Boyce, 2014).

The recommendations for lighting in work environments are usually based on the visual criteria, where the illuminance in the horizontal plane has been the main design parameter (Aries, 2005). European standard EN 12464-1 Light and lighting. Lighting of work places - Part 1: Indoor work places recommends a horizontal illuminance of $300 \mathrm{Ix}$ to $500 \mathrm{Ix}$ for the activities to be carried out in a traditional office. Considering that the non-visual biological effects of lighting depend on the amount of light, spatial and spectrum distribution, time and duration of exposure, it is not sufficient to rely solely on illuminance in the horizontal and vertical planes to develop a lighting design.

If designed correctly the work environment can has a stimulating effect on people (van Bommel; van den Beld; van Ooyen, 2002). According to Silvester and Konstantinou (2010), the challenge is to design work environments that can best meet the needs of employees and ensure maximum levels of well-being and performance. The relationships between lighting, health and security should be clear, since the amount of light added to other environmental stimuli can produce a positive or negative effect, causing changes in the mood and emotional state of the building users (Boyce, 2006; Hoffmann et al., 2008). In this sense, the employers and their employees are the direct beneficiaries, since they can achieve a work environment capable to provide well-being, security and visual comfort.

As mentioned, nowadays the work environment is not characterized by static work where people are seating in desks in front the computer without exercising many movements. The new office 
set up has created more dynamic spaces where the occupants are dislocating and in continuous movement. This makes the whole environment should be considered in research that aims to relate light, visual performance and health. Therefore, fixed measurements using luxmeter or luminancimeter in the working plane or in front of the luminaire are not enough.

The existing sensing technologies (e.g. Actiwatch-L, Daysimeter and Dimesimeter) to evaluate the indoor lighting conditions from a fixed point of view and measure the luminous quantities such as horizontal and vertical illuminance that might not necessarily reflect the actual light received by the building occupants.

Aiming to promote researches about this matter, it was designed and tailored a wearable device named OcuLux (Fig. 1), which was tested for office environment. OcuLux registers continuously the actual pupilar illuminances thanks to an RGB sensor attached on glass frames (Dias et al., 2017 ; 2019).

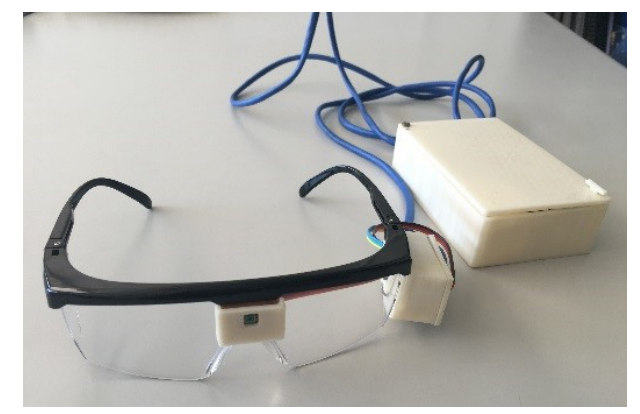

Figure 1 - Wearable device "OcuLux"

OcuLux was calibrated and tested in an office room of the Solar Energy and Building Physics Laboratory (LESO-PB) at École Polytechnique Fédérale de Lausanne (EPFL) in Lausanne (Switzerland). Two samples of the wearable device were worn simultaneously by two young females with normal vision, seated faced each other to investigate the light dose received individually along the workday. At the end of each day the participants answered an online questionnaire based on Office Lighting Survey, aiming to understand how each one perceived the lighting conditions of the room.

\section{Methodology}

\subsection{Experimental setup}

The experimental study was carried out in a south-facing office room located on the ground floor of the LESO solar experimental building (latitude: $46^{\circ} 32^{\prime} \mathrm{N}$, longitude: $6^{\circ} 36^{\circ} \mathrm{E}$, a.s.l.: 410 m) (Fig. 2). The floor area of the office room is equal to $15.7 \mathrm{~m}^{2}$ and the room height is $2.8 \mathrm{~m}$. Two LED-based ceiling luminaires are fitted in the office room and the characteristics of each of them are the following: (i) Luminous flux: $2400 \mathrm{Im}$, (ii) Energy consumption: $23 \mathrm{~W}$, (iii) Correlated Colour Temperature: $4000 \mathrm{~K}$ and (iv) Colour Rendering Index: 80 . The Unified Glare Rating (UGR) sensed by the room occupants is expected to be lower than 19 (Motamed et al., 2017).

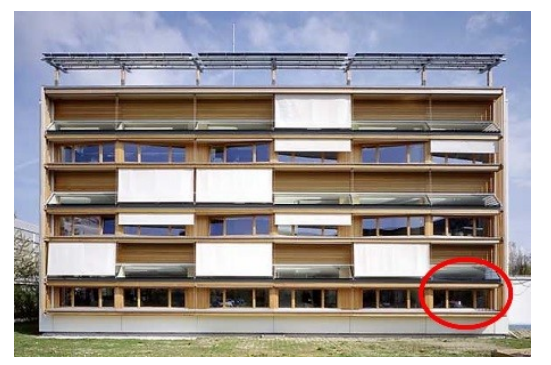

Figure 2 - South-facing office where the experimental study was carried out

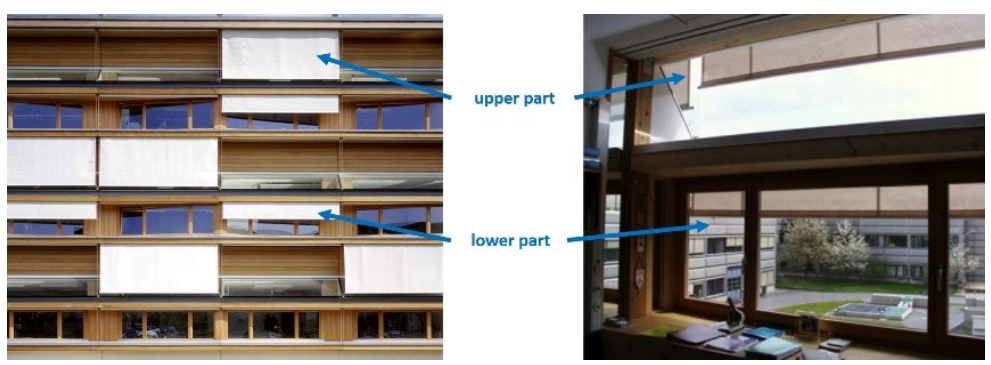

Figure 3 - Conventional window and ADS equipped with automatic motorized venetian blinds 
The room has a conventional window and an Anidolic Daylighting System (ADS) on the upper part of its high, both equipped with automatic motorized venetian blinds, which can be controlled manually by the users (Fig. 3). During the experiment, the shading system and the artificial lighting were turned on to work automatically to guarantee the visual comfort for the occupant (by minimizing glare risks) and sufficient illumination on the workstation (by optimizing the work plane illuminance). Although, the participants were allowed to manage manually the shading system and the artificial lighting using the switches located into the room in order to tune the lighting conditions.

The office room has standard office furniture, two main workstations and two HDR vision sensors. The first sensor is mounted in the ceiling and is used for assuring the required illumination on the work plane for specific work based on lighting norms (DIN EN 12464-1 Indoor Workplane Lighting). The second one is attached on the desktop (Visual Display Terminal VDT) to monitor the main photometric variables (e.g. pupilar illuminance, average luminance, etc.) as well-known glare indices, such as the Daylight Glare Index (DGI) and the Daylight Glare Probability (DGP).

\subsection{Calibration}

The calibration process of the wearable device was limited to indoor daylighting conditions (clear and overcast skies) without direct sunlight and was applied by comparing the latter one with a reference illuminance meter (T-10 by Konica Minolta, Japan) in a room at the LESO solar experimental building.

The digital output RGBraw of the sensor RGB S9706 (Hamamatsu Photonics, Japan) was translated into $R G B_{\text {linear }}$ values using photosensitivity parameters issued from the sensor's catalogue. Then, it was used an equation proposed by Jacobs (Jacobs, 2014) to convert $\mathrm{RGB}_{\text {linear }}$ values in relative illuminance values, where 179 is the assumed standard luminous efficiency (Eq. 1):

$$
Y_{\text {rel }}=179 \times\left(R_{\text {linear }} \times 0,265+G_{\text {linear }} \times 0,67+B_{\text {linear }} \times 0,065\right)
$$

where:

$$
\begin{aligned}
& Y_{\text {rel }} \text { relative illuminance; } \\
& \text { Rlinear linear value of the } \mathrm{R} \text { channel; } \\
& \text { Glinear linear value of the } \mathrm{G} \text { channel; } \\
& B_{\text {linear }} \text { linear value of the } \mathrm{B} \text { channel. }
\end{aligned}
$$

Finally, through a calibration process, the $Y_{\text {rel }}$ values were transformed using a conversion factor using the illuminance values measured by the reference illuminance meter. More details about this process can be seen in (Dias et al., 2017; 2019).

A software was developed to be used as an interface between the user and the wearable device, to facilitate the configuration for data collection (Dias et al., 2019).

The HDR vision sensors were programmed to record each 16 seconds. In this way, the same range was selected for the OcuLux records. It was selected an integration time equal to $30 \mathrm{~ms}$ and the samples with a saturation in the registry were discarded. Using a MATLAB (2016) code both OcuLux and HDR vision sensors data were grouped every minute and after such a procedure the samples were analysed.

\subsection{Experimental protocol}

To investigate the light flux that reaches the user's eyes during the work hours, two young females with normal vision (no corrective glasses) wore the OcuLux device for 5 full days from 9 AM to noontime and from 2 PM to 5 PM. The experimental study was carried out in January 2017 spanning different sky conditions (overcast, partly cloudy and clear sky). The participants' workstations were perpendicular to ADS and conventional windows and they faced each other (positions $A$ and $B$ ), as illustrated in Fig. 4. The assessment of the lighting environment in the office room was carried out by the HDR vision sensor and it was calculated the hourly light dose [lux.h], which is obtained by integrating the measured illuminance over a one hour period. A daily light dose is made of the sum of hourly light doses. 
The participants maintained a normal work rhythm and kept a schedule diary. Every day at the end of the data collecting using the OcuLux device, the subjects answered a short online questionnaire based on Office Lighting Survey to assess how each one behaves considering the light and perceives their workplace.
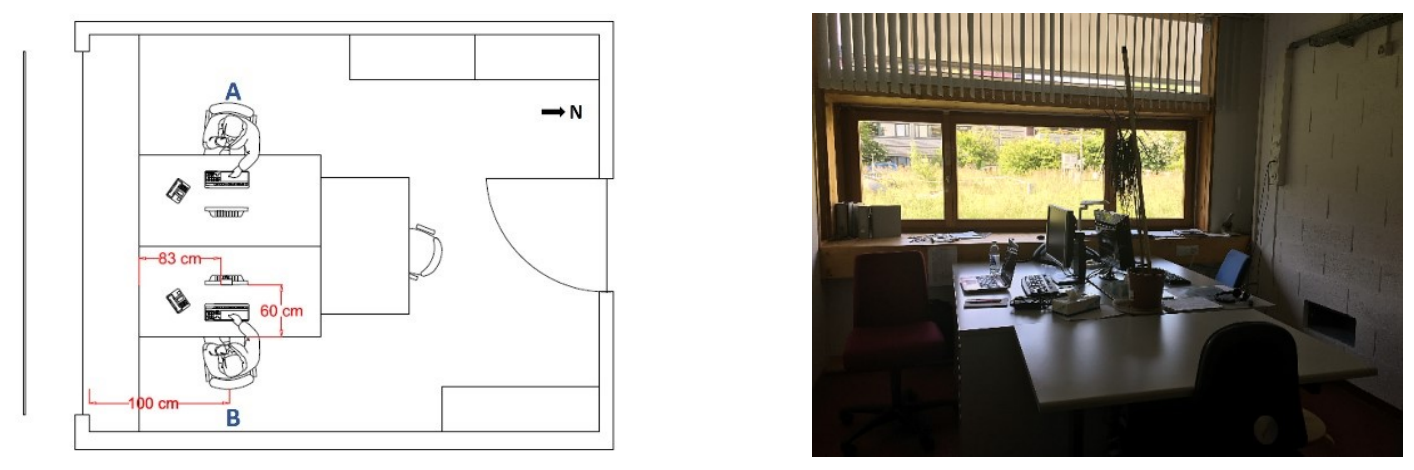

Figure 4 - Workstations occupied by the participants

\section{Results}

Data collected for days with clear sky showed that the participant who occupied the workstation $A$ received a higher light flux until 10:30 AM. After this time and until 4 PM, higher levels were recorded for the participant in workstation $B$, as can be seen on January 17 (Fig. 5). The mean pupilar illuminance recorded by OcuLux during the morning was approximately $571 \mathrm{Ix}$ in $A$ and $648 \mathrm{Ix}$ in $B$. During the afternoon the values were more similar, being $316 \mathrm{~lx}$ and $348 \mathrm{~lx}$, respectively. The HDR sensor installed on the VDT recorded a mean illuminance around $268 \mathrm{Ix}$ in the morning and $235 \mathrm{Ix}$ in the afternoon. The difference between the HDR vision sensor and OcuLux registers is due to the fact that at the time of data collection a desk lamp blocked part of the light flux incident on the sensor.

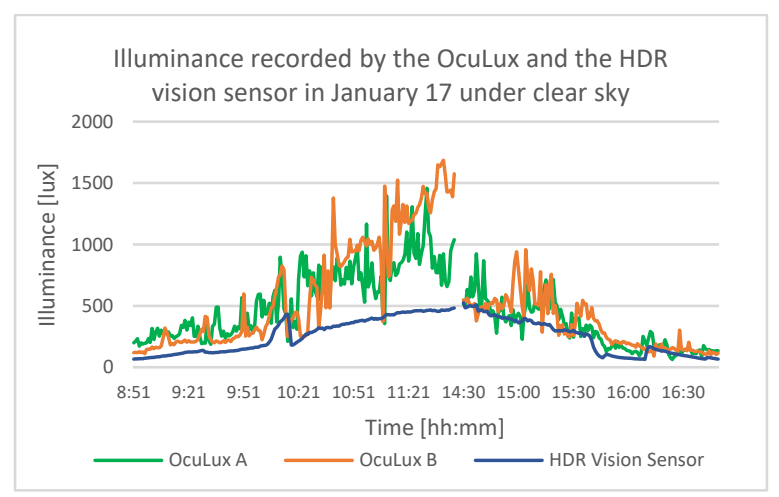

Figure 5 - Illuminance data recorded by OcuLux and HDR vision sensor under clear sky

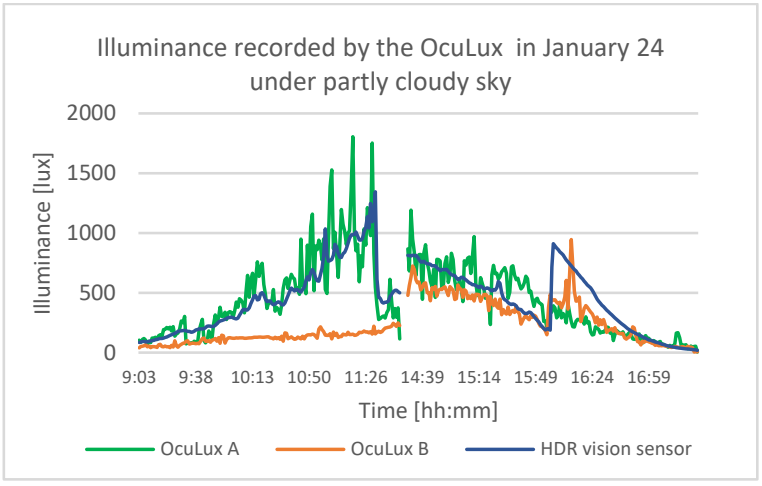

Figure 6 - Illuminance data recorded by OcuLux and HDR vision sensor under partly cloudy sky

Under partly cloudy sky the participant who occupied the workstation $A$ received a higher light flux in the visual field than the participant $B$ throughout the day. At the end of the afternoon, with the increase of sun exposure there was an increment in the record of the participant at workstation $B$ (Fig. 6). The mean pupilar illuminance registered during the day by the participant in $A$ remained closer to the mean illuminance recorded by the sensor on the VDT, being around $44 \mathrm{Ix}$ and $446 \mathrm{Ix}$, respectively. The mean pupilar illuminance registered in $B$ was $223 \mathrm{Ix}$.

Data for overcast sky indicated that the participant at the workstation $A$ received a higher light flux throughout the morning and most of the afternoon. The participant in $B$ presented the highest record from 2 PM to 3 PM (Fig. 7). Mean pupilar illuminance registered during the day was $185 \mathrm{Ix}$ for workstation $A$ and $151 \mathrm{Ix}$ for $B$, while mean illuminance recorded by the sensor on the VDT was $204 \mathrm{Ix}$. 


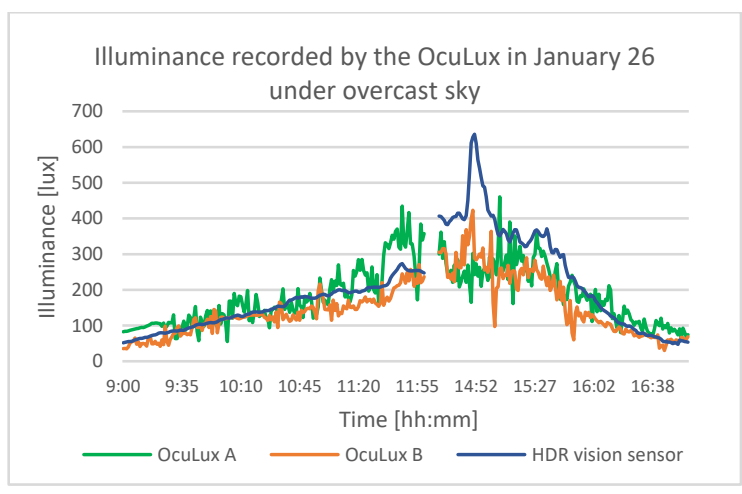

Figure 7 - Illuminance data recorded by OcuLux and HDR vision sensor under overcast sky

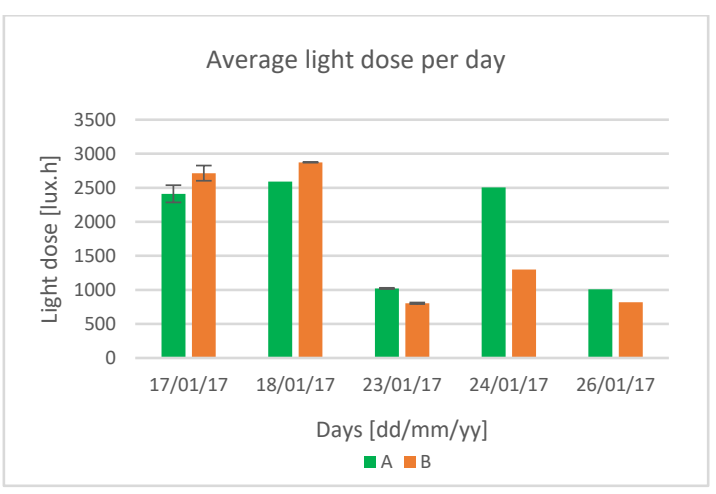

Figure 8 - Average light dose [lux.h] received by the participants during the workday

The daily light dose received by the participant in workstation $A$ during the days with clear skies (January 17 and 18) was between 2410 [lux.h] and 2590 [lux.h]. Under the partly cloudy sky (January 24) the data recorded was 2500 [lux.h], while under overcast skies (January 23 and 26 ) the light dose was around 1000 [lux.h]. The participant in $B$ position had a record ranging from 2714 [lux.h] to 2872 [lux.h] for clear skies, 1299 [lux.h] for partly cloudy sky and between 803 [lux.h] and 819 [lux.h] for overcast skies (Fig. 8). It is possible to observe that there was a significant difference in the light dose received by the participant in $B$ position in relation to participant in $A$, under partly cloudy sky. This difference is due the solar azimuth related to the façade for each one of the participants.

As participant in $B$ position occupied the workstation to the right of the window and due the angulation that the direct radiation affects the south façade, it was initially expected that the light dose received during the afternoon was considerably higher than that of the morning. However, as can be seen from the obtained data, the light dose for participant $B$ is only higher when under influence of direct solar radiation. Under partly cloudy and overcast skies, the participant in the workstation $A$ receives higher influence of diffuse solar radiation (Fig. 9 and $10)$.

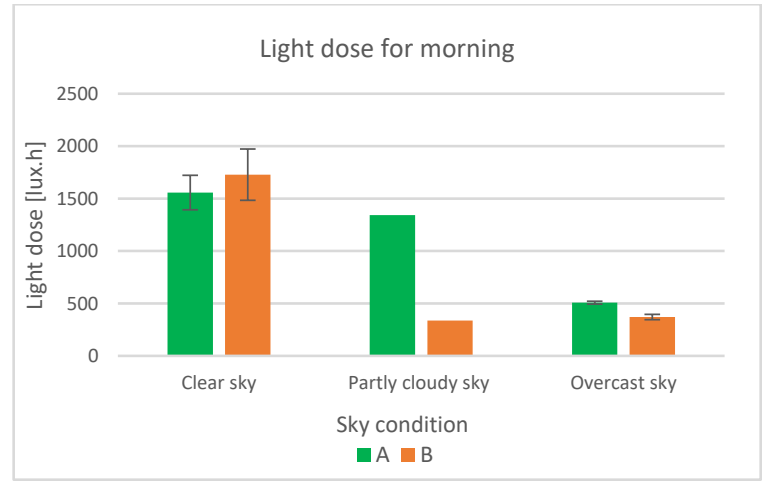

Figure 9 - Light dose received in the morning period by the participants

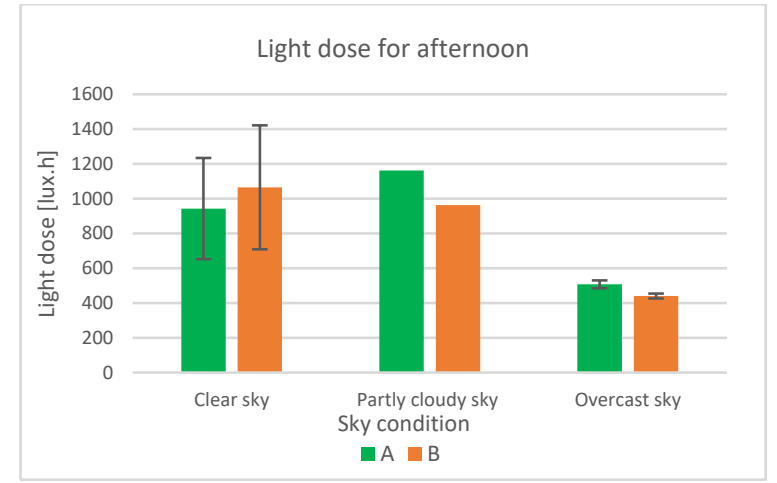

Figure 10 - Light dose received in the afternoon period by the participants

Considering that EN 12464-1 determines that the minimum $E_{\mathrm{h}}$ required in the work plane is between $300 \mathrm{~lx}$ to $500 \mathrm{Ix}$ and Salvendy (2001) recommends that for work environments illuminated by suspended luminaires the ratio between vertical and horizontal illuminance shall be between 0,3 and 0,5 , a minimum vertical illuminance equal to $150 \mathrm{Ix}$ to $250 \mathrm{Ix}(500 \times 0,3$ and $500 \times 0,5)$ must be assumed. Verifying the distribution of illuminance levels to which participants were exposed during working hours (Fig. 11), it was found that they were exposed to an illuminance between $150 \mathrm{Ix}$ and $250 \mathrm{Ix}$ in $33 \%$ of the time. Illuminances between $250 \mathrm{Ix}$ to 500 Ix were recorded in $41 \%$ of the time. 


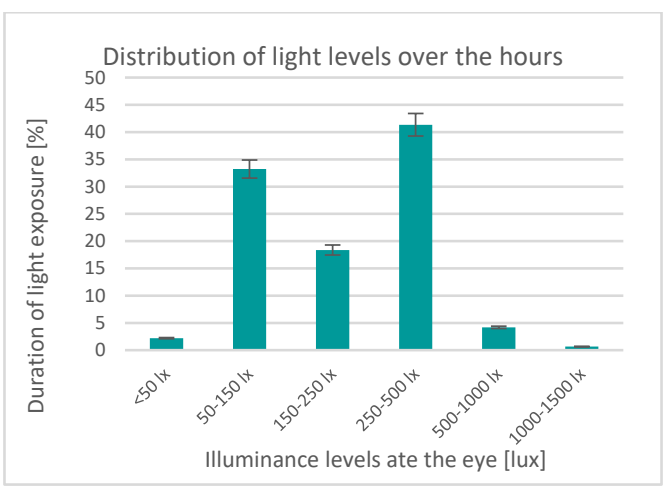

Figure 11 - Exposure time of different illuminance levels as percentage per hour

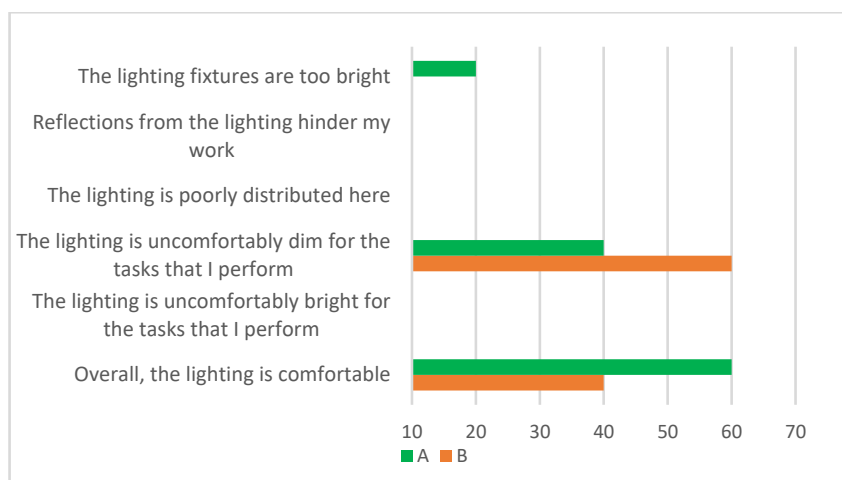

Figure 12 - Perception about the lighting work environment by the participants

According to the questionnaire filled, participant in workstation $B$ perceived the light as slightly uncomfortably than participant in workstation $A$, during the most part of the office hour. Participant in workstation $A$, otherwise, perceived lighting as comfortable, and sometimes very bright (Fig. 12). Considering the satisfaction with the daylighting in the office room, participants were fairly satisfied under clear sky lighting. However, under partly cloudy sky, participant in $A$ reported to be fairly satisfied, unlike the participant in $B$ position (Fig. 13). Regarding the light available for working/reading, participant in $B$ position reported that its conditions was poor and not very good, especially on days with partly cloudy and overcast skies (Fig. 14).

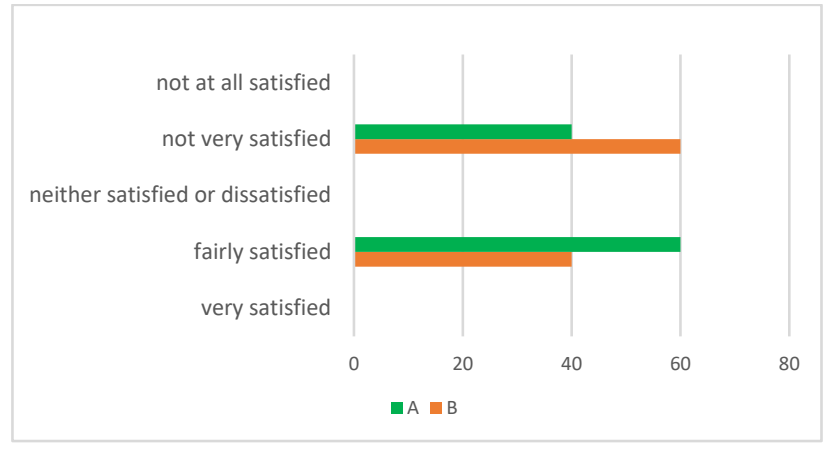

Figure 13 - How satisfied are you with the lighting in your work space

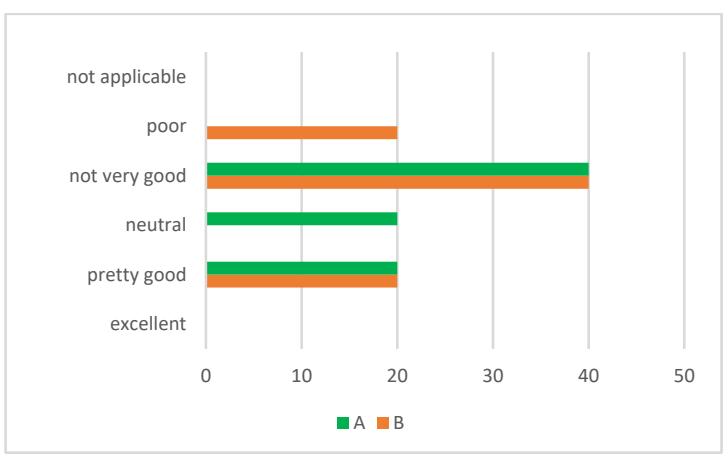

Figure 14 - The light available for working/reading is

When asked to the participants how each one felt the office environment, they related having a moderate mood in $60 \%$ of the time (fig. 15), and the participant in the workstation $B$ tended to feel more tired than the participant in position $A$, who reported being more awake (Fig. 16).

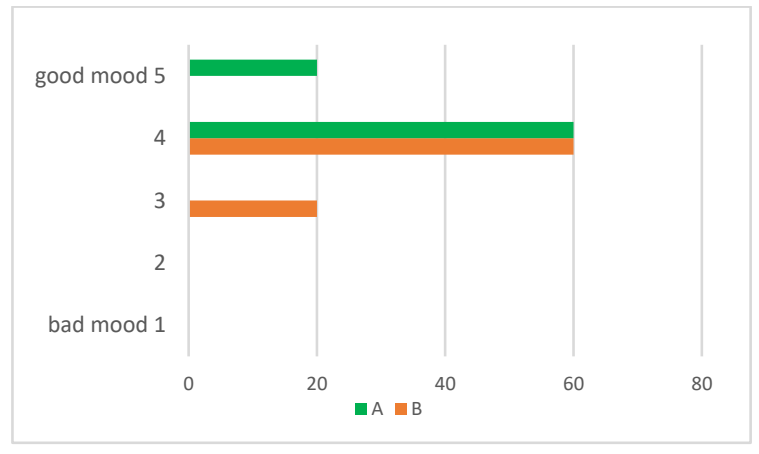

Figure 15 - How the participants felt

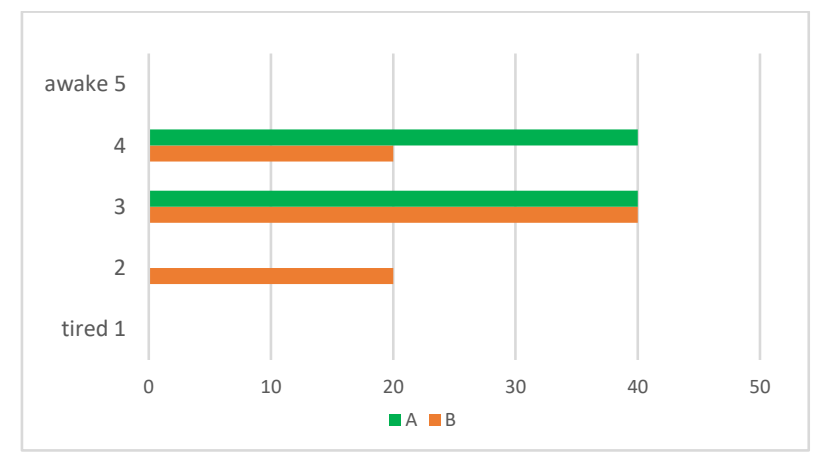

Figure 16 - How the participants felt 


\section{Conclusion}

Although OcuLux has a limited measuring range and needs some improvements such as replacing the Arduino NANO microcontroller for a more robust one, and requires a better ergonomic design for the set, the collected data had indicated that it responded consistently to variations in the light quantities in an indoor environment. Differently of current devices that aims to register influences of light on circadian rhythm, by registering body movements (e.g. Actiwatch-L, Daysimeter and Dimesimeter), Oculux measures and save in its software, the quantity of light that reaches directly the human eyes from RGB sensor. By using a simple equation, it is possible to convert the recorded data in lux, having by this way the pupilar illuminances along an office work shift, for example. More experiments are necessary, for other laboral activites, to validate Oculux as universal device destined to measure pupilar illuminances.

The application of questionnaire related to light survey showed that such tool is of fundamental importance, once it can permit a better comprehension of the interrelation among quantitative and qualitative data about an illuminated environment, concerning human well-being and health.

\section{Acknowledgements}

This research project was supported by São Paulo Research Foundation (FAPESP) grant \#2012/08887-1 and \#2015/23213-5 as well as the Commission for Innovation and Technology (CTI) of the Swiss Confederation though the Swiss Competence Center for Energy Research on Future Energy Efficient Buildings and Districts (SCCER FEED\&B).

\section{References}

ARIES, M. 2005. Human Lighting Demands: Healthy Lighting in an Office Environment. Eindhoven, $158 \mathrm{f}$. Thesis (Doctoral Program in Building Physics and Systems) - Technische Universiteit Eindhoven, Eindhoven.

BOYCE, P.R. 2014. Human Factors in Lighting. 3rd Ed. USA: CRC Press. (DOI: $10.1201 / \mathrm{b} 16707)$.

BOYCE, P.R. 2006. Lemmings, Light, and Health. Leukos, 2, 3, 175-184. (DOI: 10.1582/LEUKOS.2006.02.03.002).

DIAS, M.V.; MOTAMED, A.; SCARAZZATO, P.S.; SCARTEZZINI, J.L. 2017. Toward Proper Evaluation of Light Dose in Indoor Office Environment by Frontal Lux Meter. Energy Procedia, 122, 835-840. (DOI: 10.1016/j.egypro.2017.07.418).

DIAS, M.V.; MOTAMED, A.; SCARAZZATO, P.S.; SCARTEZZINI, J.L. 2019. Wearable Device for Measuring Pupilar Illuminance. Ambient Constr., 19, 2, 129-143. (DOI: 10.1590/s167886212019000200312 ).

DIN 2013. DIN SPEC 67000: 2013. Biologically Effective Illumination: Design Guidelines. Berlin: DIN.

EN 2011. EN 12464-1:2011. Light and Lighting: Lighting of Work Places: Part 1: Indoor Work Places. Brussels: EN.

HOFFMANN, G.; GUFLER, V.; CRIESMACHER, A.; BARTENBACH, C.; CANAZEI, M.; STAGGI, S.; SCHOBERSBERGER, W. 2008. Effects of Variable Lighting Intensities and Colour Temperatures on Sulphatoxymelatonin and Subjective Mood in an Experimental Office Workplace. Appl Ergon., 39, 719-728. (DOI: 10.1016/j.apergo.2007.11.005).

JACOBS, A. 2014. Radiance Cookbook. United Kingdom: Jaloxa. Available at: <http://www.jaloxa.eu/resources/radiance/documentation/docs/radiance_cookbook.pdf>. Accessed in: 29 out. 2016.

MATLAB. 2016. R2016b version. Massachusetts: The MathWorks. 
MOTAMED, A.; DESCHAMPS, L.; SCARTEZZINI, J.L. 2017. On-Site Monitoring and Subjective Comfort Assessment of a Sun Shadings and Electric Lighting Controller Based an Novel High Dynamic Range Vision Sensors. Energy Build., 149, 58-72. (DOI: 10.1016/j.enbuild.2017.05.017).

SALVENDY, G. 2001. Handbook of Industrial Engineering: Technology and Operations Management. 3rd Ed. New Jersey: John Wiley \& Sons. (DOI: 10.1002/9780470172339.ch80).

SILVESTER, J.; KONSTANTINOU, E. 2010. Lighting, Well-Being and Performance at Work: A Review of the Literature. London: City University.

van BOMMEL, W.J.M.; van den BELD, G.J.; van OOYEN, M.H.F.2002. Industrial lighting and productivity. The Netherlands: Philips Lighting. 